\title{
The Comparative History and Development of E-commerce in China and the United States
}

\author{
Ruofan Shen \\ Washington and Lee University, Virginia, USA \\ Shenr20@mail.wlu.edu
}

Keywords: E-Commerce, China, America, Logistics, Technology, Culture

\begin{abstract}
This research aims to investigate the differences between e-commerce in two countries, the origins of those differences, and what they can say about the future of E-commerce. While China is among the developing countries in Asia, the US has the greatest power to affect global market. By analyzing previous research on E-Commerce, we have concluded the main differences between logistics and payment, legalization and technology, and cultural contents. Also, we predicted that $\mathrm{B} 2 \mathrm{C}$ will become the dominating force and ultimately surpass $\mathrm{C} 2 \mathrm{C}$ in China.
\end{abstract}

\section{Introduction}

Global electronic commerce is growing exponentially, especially in the US and China. By June 2017, the number of internet users in China reached 751 million, an increase of 92 million in the past 6 months. In addition, the Internet penetration rate was $54.3 \%$, up 1.1 percentage points from the end of 2016. China's high population along with the rapidly increasing number of internet users have created huge potential for China's online consumption, which is predicted to grow at an annual rate of $17.4 \%$. Despite the impressive statistics, China is still behind the US in e-commerce. Although China and the US have the same E-Commerce market share, 7\% of America's global transaction rate is still the largest in the world. Meanwhile, US tech giant Amazon remains ahead of its Chinese competitor Alibaba, staying on top of the market in Europe and in the US with a revenue of \$136 billion in 2016 alone. Historically, the concept of e-commerce emerged around the same time in both countries. However, the method through which these markets were developed were entirely different. This paper explores the history between China and the US and the main differences in business structure, global influence and timing. Finally, we conducted a deeper analysis on factors that caused these differences and later concluded that compared to the U.S, there is huge opportunity for Chinese e-commerce to take off, however, improvements need to be made in governmental support, logistics management, and user management protocols.

\section{Historical Review}

\subsection{The History of E-commerce in China and the U.S}

Chinese e-commerce emerged in 1997-1998, when IT vendors and media dominated the industry. During 1999-2000, the main adopters of electronic commerce were e-commerce sites. In 2001, ecommerce enterprises took on the role of taking advantage of mass internet adoption and dominated the market. The Electronic Signature Law of the People's Republic of China was later adopted in 2004, which signaled an awareness from the Chinese government of the growth prospects of ecommerce. As of 2018, many famous e-commerce enterprises have emerged in China, but only $25 \%$ of the 10 million small and medium-sized enterprises use e-commerce.

Currently, China's e-commerce is in a stage of rapid development. In 2010, e-commerce transactions totaled more than 3.8 trillion yuan, and online transactions totaling 576.6 billion yuan. A series of online procurement markets, such as Alibaba, China railway network and China chemical network emerged. 


\subsubsection{The Development of China's E-Commerce}

In 2017, China's e-commerce penetration rate reached 20\%, which was the highest in the global market and the fastest growing. In 2017, China's B2C e-commerce grew by $28 \%$ year on year, and mobile terminals contributed $73 \%$ of GMV. In addition, Chinese e-commerce is also reconstructing the retail market experience by using technology to re-structure traditional industries.

China is a communist state with a population of 1.388 billion people. It has a GDP of $\$ 11.8$ billion USD, which represents a GDP per capita of \$8,480.65 USD in 2017. In 2017, the B2C ecommerce grew by $19.96 \%$ to $\$ 681.9$ billion USD. In addition, China has an online population of 583.1 million people aged 15 and older. Of the total online population, 413.3 million bought something online in 2015. The average spending per online shopper was $\$ 1,505$ USD in this year. Figure 1 shows the gross merchandise volume of China's e-commerce market.

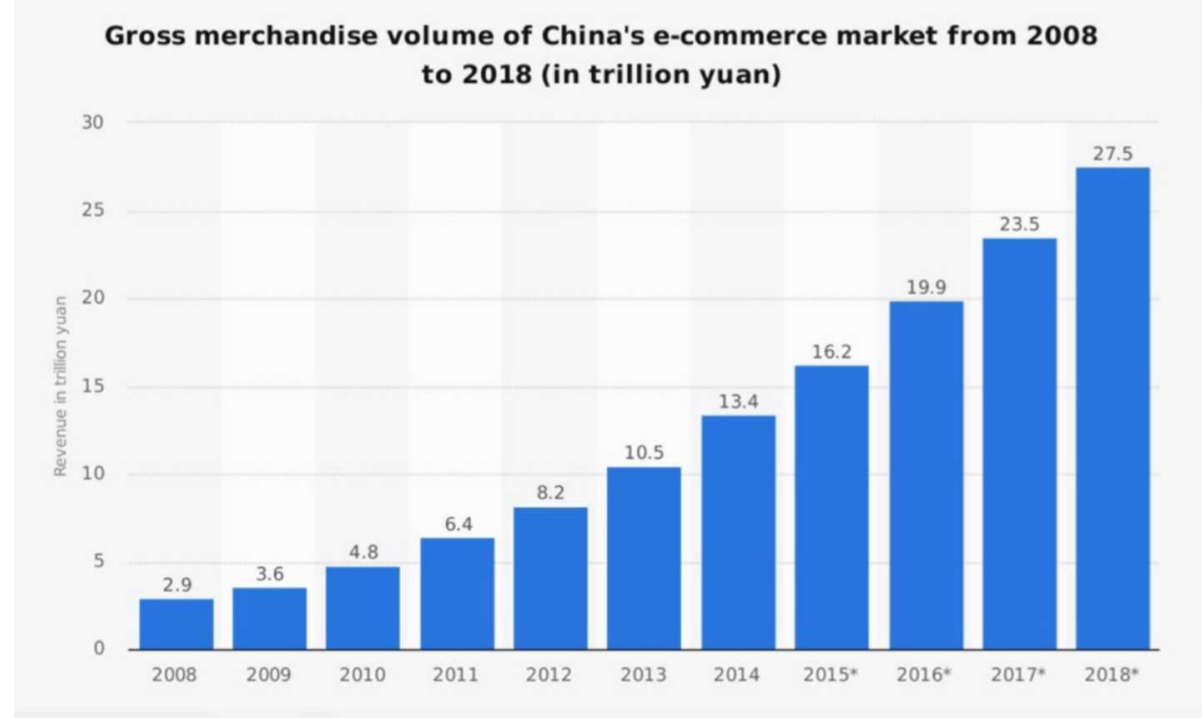

Fig. 1. Gross merchandise volume of China's e-commerce market from 2008 to 2018 (in trillion yuan)

\subsubsection{The Development of America's E-commerce}

In 1980, America's first large commercial chain, Walmart, began using a precursor to e-commerce, Electronic Data Interexchange (EDI) with suppliers. By 1993, there were 23,000 companies using EDI in the United States. The concept of e-commerce did not emerge until 1996. In 1997, the United States government issued the outline of global electronic commerce. In 2000, the Electronic Signature Act became part of federal law, aiming to facilitate the use of electronic records and electronic signatures in interstate and foreign commerce by ensuring the validity and legal effect of contracts entered electronically. As of 2018, 80 percent of U.S. manufacturers had their own web sites, 60 percent of small businesses, 80 percent of medium-sized enterprises, and 90 percent of large companies already had e-commerce.

\subsection{Similarities and Differences}

Judging from the history of both countries, e-commerce has developed rapidly in Ameri-ca and China in just over a decade. Both the US and China have enacted laws on the legality of e-commerce. Both the American and Chinese e-commerce market is monopolized by large enterprises, while small and medium-sized enterprises have a small market share.

However, the development of e-commerce in China and the U.S have a lot of differences. The two countries differ first in how businesses are structured. In America, it is more prevalent to have B2C (Business to Consumer), which is also the dominating structure of the global market. In China, however, based on the unique business environment, the primary method to conducting e-commerce is $\mathrm{C} 2 \mathrm{C}$ (Consumer to Consumer).

A second difference is that the United States has more influence globally than China. Although China and the US have the same market share in e-commerce which is $7 \%$, the global transaction rate of e-commerce in the US is the largest in the world. Over $90 \%$ e-commerce websites are from the US, 
the transaction rate is over $50 \%$ above the global average. Moreover, the size of e-commerce market in the United States, which accounts for more than 50\% of global e-commerce transactions, is far ahead of the market in China. The level of e-commerce development of China is only 0.23 percent of the United States. Despite that, China in 2013 became the largest online retail market in the world, which to some extent could signal its rising global influence.

Third, the concept of e-commerce in China did not gain adoption as quickly as it did in the US. In the 1980's, Walmart had used EDI, which is very similar to the idea of "e-commerce" nowadays to sell its products. The emergence of e-commerce received a lot of attention from people, and the US government was also a big proponent of e-commerce. China, however, introduced e-commerce in 1997. Conversely, the emergence of electronic commerce had not caused a sensation, until 2000, when Jack Ma, the founder of Alibaba, proposed to establish an e-commerce company, but didn't receive any support from the people or the government.

\section{Economic Analysis}

\subsection{Logistics and Distribution systems}

Logistics is considered a source of advantage and the efficiency of the distribution network is considered a success factor for firms in the e-commerce market. In addition, e-commerce shipments require an entirely new distribution infrastructure to handle online business.

The scale of the US logistics industry is about $\$ 900$ billion, almost twice the size of the high-tech industry and more than 10 percent of US gross domestic product. Moreover, the logistics industry has good market segmentation, which includes wholesale, retail and warehousing. Many US enterprises have advanced distribution systems. For instance, Amazon has its own distribution center, with a variety of payment methods, and free distribution of products within a certain amount. The number of its distribution centers has grown from 8 centrally located centers in 2006 to 90 across the US by the end of 2016. Amazon planned to further expand its network to over 100 facilities by the end of 2018, including "Amazon Now" hubs that provide same-day delivery to local customers.

During recent years, the Chinese logistics industry has developed far more rapidly than its GDP. Since China joined the WTO, logistics has been one of the earliest industries to participate in international competition. Simultaneously, many foreign logistics companies and transportation giants are taking advantage of China's logistics market. Many larger chains and online retailers from outside China have established their own distribution centers in the country. Moreover, most nonChinese logistics companies have established partnerships with existing Chinese third-party logistics service providers. These third-party providers have identified the most appropriate locations for the distribution network. While China is making progress in logistics, China's express delivery industry, a big part of the logistics industry, lacks a clear market accession system, standards and norms for the restriction and evaluation of the quality of enterprises, leaving an opportunity for improvement in the e-commerce industry.

\subsection{Payment Methods and Infrastructure}

Statistics show that payment methods for online shopping in China and the US are very different. The rise of new online payment methods such as AliPay and Wechat Pay brought convenience and popularity to online shopping in China. In 2017, China's mobile payment scale increased by $209 \%$ year on year, and the growth rate continued to in-crease. WeChat accounts for $38 \%$ of China's mobile payments market, while Alipay accounts for $54 \%$. While in the US, users are already accustomed to the online payment system for buying goods, which gives an advantage to Amazon.

China's infrastructure including payment system is rapidly growing. Fast and reliable payment systems have reached every part of the country. Once companies realize that online payment systems are a profitable business to be in, they will take part in the improvement of the systems proactively. For example, Alibaba provides various types of payment systems, including Alipay, Quick-pay, online banking, credit card, debit card, and so on. These payment systems are able to cope with simultaneous transactions with ease. 
The US credit system is much more transparent than in China. Everyone in the United States has a credit card, which records the holder's social security number and settles e-commerce transactions. Meanwhile, people in the US are concerned with privacy protection. In America, more than $60 \%$ of the e-commerce sites do not need member registration. When they require users' personal information, they have to provide a privacy policy: a series of protection measures to protect the security of transactions and confidentiality of information. In China, the government doesn't pay enough attention to privacy, thus many sites lack security, authentication, encryption and privacy protection measures. As a result, the loss of customer information threatens the health of e-commerce in China.

\subsection{E-commerce Accessibility}

In the 21 st century, the internet exceeded a hundred million and the popularity of the internet increased. As more people adopt the internet, more people are gaining accessibility to online shopping. Compared to China, the American computer and internet penetration rate is very high, and most children can surf online easily on a computer in the classroom or in the library. For now, China's penetration rate is only about $16 \%$ compared to the world standard $19.1 \%$ and the US's $69.7 \%$, according to China Internet Network Information Center.

The increasing growth of internet users was essential in developing the Chinese e-commerce market. Although compared to the US, the amount of internet users in China is lower, with the development of the computer network in rural areas, the number of internet users in China is predicted to exceed a billion in 10-20 years, which is 4 times of that of the US. China's large population has created a significant potential for online consumption.

\subsection{The Rule of Law}

The strength of the law affects transactional integrity in e-commerce, and investment in these markets. As consumers migrate to the Web, they are more likely to turn to companies from countries where transactional integrity is greater, and in particular to firms whose reputation is well established.

The U.S. government emphasizes the growth of the e-commerce market through encouraging private enterprises to play a leading role and minimizing government intervention. At the same time, in terms of tax policy, the government has created the most favorable space for e-commerce development. Putting a lot of emphasis on infrastructure, on 22 May 1998, President Clinton issued two Presidential Decision Directives (PDD), which involved network infrastructure and information security, to strengthen and coordinate critical infrastructure defense programs. In addition, the government places importance on privacy protection and consumer rights.

Compared to the U.S., the prosperity of e-commerce in China requires additional legal support. Since the Chinese regulators lack a cooperation and coordination mechanism, e-commerce legislation is far behind industrial development. On February 18, 1994, the State Council issued regulations on the protection of the computer information system in the People's Republic of China. Over the years that would follow, the policy of network information security also appeared with administrative enforcement. However, due to the lack of relevant laws, network security relies mainly on the technical strength of the individuals that protect their privacy. At the same time, due to the lack of authoritative electronic commercial arbitration institutions, the rights and benefits of buyers and sellers are not guaranteed, which increases the transaction cost of international trade. Although Chinese officials have stated they are committed to improving their protection of intellectual property and liberalizing their economy, e-commerce legislation is still far behind China's industrial development.

\subsection{Culture Content}

The main cultural differences lie in a reputation system, differences in social values and relationships between individuals and businesses.

The development of e-commerce requires a high level social reputation system. In the US, reputation had been important many years ago since the inception of the e-commerce. Compared with 
the US, China had serious defects which constrain the development of e-commerce, a complete reputation system hasn't yet formed.

People who shop online have different characteristics in both countries. In 2000, Only $31.9 \%$ of Chinese internet users had experience online shopping. In the U.S., however, $82 \%$ of internet users had purchased at least one product or service online. The statistics that only 2.5 percent of the whole population are online in China reflect that China's ecommerce is still stagnant, while in the U.S., internet users now comprise half of the entire US population. In China, female internet users are increasing rapidly. According to the "Statistical Report on Internet Development in China" by CNNIC, 38,7\% of internet users in China are women. Also, Chinese internet users tend to be younger than those in the Unit-ed States.

Chinese society has also indirectly shaped their relationship with merchants by focusing more on social relations. In addition, Americans prefer to use the e-commerce system it-self, while Chinese people prefer to deal with familiar businesses. Trademarks and intellectual property have always been one of the main components of innovation. While the US pays more attention to protecting the origin of the product as intellectual property, China likes "shanzhai" (Chinese imitation and pirated brands and goods, particularly electronics), but this has changed in recent years.

\section{Cross-border}

\subsection{History}

First stage (bud, 1997-1997): Cross-border e-businesses began in China at the end of the 20th century. It aims at helping small and medium-sized enterprises export a B2B plat-form. The representatives are Alibaba international, China manufacturing network, etc. From 1997 to 1999, China's foreign trade B2B e-commerce sites in the China chemical network, China manufacturing network, Alibaba set up the cross-border electric business platform for small and medium-sized enterprises to provide basic services such as commodity information display and deal making. Alibaba is generally known as the largest cross-border B2B platform in the world and has gradually developed from an online $\mathrm{B} 2 \mathrm{~B}$ information service platform to $\mathrm{B} 2 \mathrm{~B}$ cross-border online trading platform.

Second stage (development period, 2008-2013): With the improvement of the global internet penetration rate and cross-border payment, logistics and other services, Chinese cross-border electronic retail businesses (B2C/CSC) flourished. Facing fierce overseas competition, DX (2006), the LAN pavilion preface (2007), Ali speed sell tong (2009) con-formed to the growth trend of crossborder electronic B2C website. The development of cross-border e-commerce retail market has led to changes in international trade bodies, trade modes and so on.

The third stage (outbreak since 2014): The Chinese government has conducted several regulatory system innovations on cross-border electronic retail business, promoting rapid development in China's cross-border e-commerce retail import. The development of China's cross-border ecommerce gave birth to a large number of cross-border electricity re-tail platforms and enterprises, including international day cat, Netease koala, gather beauty is superior, the wharf, the little red book, etc., the industry attracted explosive growth in 2015 .

\subsection{Current Status}

Today, China's cross-border e-commerce is dominated by export companies. In 2015, the export turnover of cross-border e-commerce accounted for $83.1 \%$ of the total cross-border e-commerce transactions and $16.9 \%$ of the imports. The share of cross-border e-commerce imports is expected to rise to $25 \%$ by 2020 . According to business model, China's cross-border e-commerce is mainly B2B, accounting for $84.3 \%$ of total cross-border e-commerce in 2015, and cross-border e-commerce retail only accounts for $15.7 \%$. However, cross-border e-commerce retail sales are growing rapidly and are expected to account for more than $30 \%$ by 2020 .

In 2015, China's cross-border e-commerce retail turnover reached 752 billion yuan, an increase of $69 \%$ year-on-year. Among them, cross-border e-commerce retail exports reached 503.2 billion yuan, up about $60 \%$ year on year. Cross-border e-commerce retail imports totaled 248 billion yuan, up about 
$92 \%$ year on year. China's cross-border e-commerce retail sales are expected to exceed 3.6 trillion yuan by 2020 , an average annual increase of $37 \%$ in the $2015-2020$ range. According to the calculation, cross-border e-commerce retail exports will reach 2.16 trillion yuan in 2020, with an annual growth rate of about $34 \%$. In 2020, cross-border e-commerce retail imports totaled 1.5 trillion yuan, an annual increase of about $43 \%$.

\subsection{Growth Strategy and Potential}

\subsubsection{Advanced Technology}

Cloud computing and intelligent terminals are the foundation for the mass adoption and technological development of the internet. In the traditional industrial era, transnational enterprises dominate international trade, thus it is difficult for consumers and small enterprises to obtain sufficient market information, nor do they have the conditions to engage in cross-border e-commerce. In this century, the internet and global business plat-forms have made significant progress in giving smaller enterprises more accessibility to conduct business cross-border. The information obtained by the market main body is rich and symmetry and has almost no cost. $\mathrm{C} 2 \mathrm{~B} / \mathrm{C} 2 \mathrm{M}$ consumer demand largescale flexible production has gradually become a reality. The payment system is becoming more comprehensive; logistics aging and cost reduction are increasing; cloud computing and big data are becoming increasingly important, and cross-border trade professional services are developing rapidly. These conditions have developed a solid foundation for the rise of cross-border e-commerce.

\subsubsection{Consumption Upgrade}

The main driver of China's economic growth is consumption. The contribution of consumption to China's national economic growth in 2015 further increased to $66.4 \%$ and will continue to increase in the future. China is facing a new round of transformation in consumption. By 2020, China's middle class and above will be close to 200 million households. Consumers in overseas long tail, high quality, low price, the demand of the individualized product is becoming increasingly strong.

Over the next five years, e-commerce will account for $42 \%$ of the increase in private consumption. The large scale of online shopping users is the basis for e-commerce to create new consumption opportunities. By the end of June 2016, China's shopping network had 448 million users and 63 percent engaged in online shopping.

\subsubsection{Industry Foundation}

There are about 5 million small and medium-sized enterprises in China's foreign trade, accounting for $60 \%$ of total foreign trade. As the "seller" of "selling the world," small and medium-sized enterprises have joined the cross-border e-commerce market, which is essential for the rapid development of cross-border e-commerce export. China has the advantage of exporting products with a traditional manufacturing base, with world-class design, technology and manufacturing industry. Moreover, China is the world's largest producer in clothing, shoes and hats, luggage and bags, 3C digital, household appliances and other consumer goods.

\subsubsection{Credit Guarantee}

From the development course of China's cross-border e-commerce, the credit system and guarantee of transactions are not only crucial to the development of Taobao and other retail platforms, but also play an important role in the development of cross-border e-commerce B2B. Although China's crossborder e-commerce B2B platform started early, it did not establish a credit guarantee system in the past, and overall development has been slow. Since 2015, China's cross-border electricity B2B platform, represented by Ali international, has shifted from an information service platform to a trading platform. The shift was accumulated by corporate transactions and credit data. The crossborder e-commerce platform can obtain real transaction data of enterprises through services such as "customs clearance, inspection, taxation and remittance" provided by a comprehensive appearance service platform. It helps enterprises establish a global network trading credit system, to better obtain trust and orders from international buyers, let credit equal wealth, and form a virtuous circle. 


\subsection{E-Commerce Connectivity Index between China and Major Economics}

To reveal China's close trading relationship with other countries, we primarily use China as a reference here to compare with other countries.

\subsubsection{Research Method}

The ECI total index consists of ECI import index and the ECI export index. Each index takes into account both the absolute value of cross-border e-commerce and the potential value of cross-border e-commerce penetration between the country and China.

In 2015, among G20 countries, the ECI cross-border e-commerce connectivity index ranking of relevant countries with China was: US, UK, Australia, France, Italy, Japan, Canada, Germany, South Korea, Russia, India, Turkey, Brazil, South Africa, Mexico, Indonesia, Argentina, Saudi Arabia.

$$
\text { ECI total index }=\text { ECI import Index }+ \text { ECI export index }
$$

\subsection{Prediction}

Cross-border e-commerce B2B platform will be upgraded from an information platform to a trading platform. By providing comprehensive foreign trade services, it will be beneficial for cross-border ecommerce platforms to accumulate real trade data, help foreign trade enterprises establish a global network trading credit system and reduce international trade risks. Simultaneously, cross-border ecommerce platforms can make efficient trade matching based on big data, innovate credit guarantee services, provide support services such as finance and logistics, along with creative methodologies that will enable growth in this space.

Production enterprise is connected directly to the terminal consumer, according to real-time demand of consumers and market to realize the customization and pull the flexibility of production and supply, and based on a global business platform, and professional service providers together, forming a network of production and service together. Cross-border electricity retail on the basis of the internet and big data, will gradually develop in-to a B2B par with one main way of global trade, on the one hand will replace traditional B2B trade, on the other hand will produce a large number of new trades. This is a major trend of business development brought about by technological revolution, which cannot be reversed.

The cross-border e-commerce service ecosystem will be more prosperous. Cross-border financial services, cross-border logistics services, integrated services of foreign trade, cross-border electricity derivative services (operations, search keyword optimization, personnel training and consulting, etc.), big data and cloud computing, etc., will be around cross-border electric business platform to facilitate rapid development.

Cross-border e-commerce will promote the formation of new international trade rules and new order in the internet era. By 2020, there will be more than 900 million cross-border electricity consumers around the world, global cross-border electricity retail will become an important part of international trade, it represents the age of the internet global trade body and opportunities in changing how enterprises trade. Therefore, the international community needs to innovate the trading system, rules and standards to adapt to the rapid development of the global internet economy and cross-border e-commerce.

\section{Discussion and Prediction (B2B \& C2C)}

Both $\mathrm{B} 2 \mathrm{~B}$ and $\mathrm{B} 2 \mathrm{C}$ have a significant potential for future development, while B2C de-pends largely on $\mathrm{B} 2 \mathrm{~B}$, that is, $\mathrm{B} 2 \mathrm{~B} 2 \mathrm{C}$. For consumers, B2C is within reach, and B2B is too unfamiliar. However, a well-functioning B2C enterprise must have strong support from B2B, which depends on integration of resources within the enterprise. IT systems in traditional manufacturing, manufacturing, or retail enterprises are also difficult to under-take B2B responsibilities. Compared with B2C and B2B, the road is tenuous. $\mathrm{C} 2 \mathrm{C}$ must rely on certain platforms (such as Taobao at present) to play the long tail effect and have its own place, but the potential is limited. Table1 is an overview of China's ecommerce in 2017. 
Take the US for example: compared with the performance of eBay and Amazon, eBay is decreasing, while Amazon is ascending. eBay and Amazon are typical $\mathrm{C} 2 \mathrm{C}$ and $\mathrm{B} 2 \mathrm{C}$ examples. It can be said that the competition between them is reminiscent of the typical e-commerce model. If you look at e-commerce in the United States, you can see that there are many other companies like Amazon. Although they are not as big as Amazon, they are popular, and eBay is obviously in decline. In addition, it can be found from market share distribution of American e-commerce that the shopping share of $\mathrm{B} 2 \mathrm{C}$ also exceeds that of $\mathrm{C} 2 \mathrm{C}$.

$\mathrm{C} 2 \mathrm{C}$ has many inherent flaws that are difficult to reconcile, such as counterfeit goods, credit card hype and so on. V2V merchants are mainly individuals or small and medium-sized enterprises, and their small-scale operation has contributed to the issues that exist in the $\mathrm{C} 2 \mathrm{C}$ market. On the surface, $\mathrm{C} 2 \mathrm{C}$ has a great price advantage, but in fact, $\mathrm{C} 2 \mathrm{C}$ price cannot be lower than $\mathrm{B} 2 \mathrm{C}$ price. On the one hand, as a channel merchant, $\mathrm{B}$ of $\mathrm{B} 2 \mathrm{C}$ has a greater right to negotiate with the manufacturer, and the price is much lower than that of $\mathrm{C}$ of $\mathrm{C} 2 \mathrm{C}$.

$\mathrm{B} 2 \mathrm{C}$, on the other hand, as the primary channel and directly engages with manufacturers and consumers to reduce many intermediate links and cost, and due to size effect, also has a big advantage on how to allocate the costs. It now looks as if the price of goods on the $\mathrm{C} 2 \mathrm{C}$ platform may be lower than that of B2C. The reason is that it is either counterfeit or via informal channels. Compared with $\mathrm{C} 2 \mathrm{C}, \mathrm{B} 2 \mathrm{C}$ not only has a price advantage, but also provides better pre-sales and after-sales services, and product quality can be guaranteed. From the perspective of consumers, B2C is closer to the needs of consumers, especially with continuous improvement of living standards, and the demand for the quality of goods and services will become higher.

Table 1. 2017 China's e-commerce overview

\begin{tabular}{|l|l|}
\hline B2C Ecommerce Turnover & $\$ 681.9$ billion USD \\
\hline B2C Ecommerce growth & $19.96 \%$ \\
\hline Online population & 583.1 million \\
\hline Number of eShoppers & 413.3 million \\
\hline Most popular payment method & eWallet \\
\hline
\end{tabular}

\subsection{Fusion}

$\mathrm{C} 2 \mathrm{C}$ and $\mathrm{B} 2 \mathrm{C}$ models will gradually merge. $\mathrm{C} 2 \mathrm{C}$ operators began to development from other modes, such as $\mathrm{B} 2 \mathrm{C}$, which can not only realize complementarity, but also provide a new profit model for $\mathrm{C} 2 \mathrm{C}$. $\mathrm{C} 2 \mathrm{C}$ platforms contain additional value. As the $\mathrm{C} 2 \mathrm{C}$ e-commerce transaction scale and the expansion of the user, $\mathrm{C} 2 \mathrm{C}$ shopping websites in addition to carrying trade function, also master the acquisition of large numbers of users along with data. However, despite the advantages $\mathrm{B} 2 \mathrm{C}$ has, the line between B2C and C2C is blurring. Some B2C e-commerce websites have begun to get involved in the field of $\mathrm{C} 2 \mathrm{C}$ e-commerce, and $\mathrm{C} 2 \mathrm{C}$ platforms has also begun to enter the $\mathrm{B} 2 \mathrm{C}$ market with complementary resources.

There are more products in the $\mathrm{B} 2 \mathrm{C}$ market, more industries involved, and more products on $\mathrm{B} 2 \mathrm{~B}$ websites. Although in the past few years the domestic B2C development unsatisfactory, but traditional enterprises in the electronic commerce power, gradually showing that brands and distributors are actively exploring business online, more traditional enterprise e-commerce marketing.

In the analysis of B2B, B2C and $\mathrm{C} 2 \mathrm{C}$ e-commerce markets, the boundaries between $\mathrm{B} 2 \mathrm{C}$ and $\mathrm{C} 2 \mathrm{C}$ are increasingly blurred. The momentum of the $\mathrm{B} 2 \mathrm{~B}$ market is that the supply chain is working more closely and efficiently. The integration of the three e-commerce markets is inevitable. The competitive commanding point of future e-commerce platform lies in the competition between different e-commerce markets. For example, the Alibaba group has formed an e-commerce business 
ecology with its establishment of Alibaba, Taobao, word-of-mouth network and Ali mother, which were gradually integrated.

Integration is only a process, "relationship" is a tool, the ultimate goal is to form the net-work ecommerce ecology. The key to integration of different e-commerce markets is the integration of people and formation of relationships between them. Integration drives the effective development of e-commerce, but it is not the ultimate goal. The core of integration is to resume the ecology of online business and form an ecological chain of online e-commerce.

Providers from $\mathrm{B} 2 \mathrm{~B} 2 \mathrm{C}$, from raw material to the manufacturer, from manufacturers to wholesalers, the wholesalers and retailers, and retailers to consumers, will form the net-work electronic commerce chain, to promote efficient transactions. In this process, the friendship, business relationship and trading relationship between people are important. The social networking of e-commerce has become key to integrating e-commerce.

E-commerce has become the best practitioner of social networking. Social networking is still looking for a viable revenue model. Its praise for word-of-mouth marketing has not yet been widely used. On the contrary, e-commerce enterprises are more likely to take advantage of word-of-mouth marketing.

According to China's Internet survey data, word of mouth is the most important source of consumer information for internet user shopping. Before shopping, many users will refer to their shopping decisions through the evaluation of search products, and users will trust their friends' word-of-mouth more than any advertisement. For electronic commerce enterprise, e-commerce sites are not the user shopping last mile, even if the user to your site, users need to compare, analyze, and at that time, word of mouth will become an important reference for decision making when shopping.

Whether B2B, B2C or C2C, we can make use of the word of mouth and place it in a system to integrate it into the consumer process, to provide user with efficiency while shopping. In addition, when using social networks, e-commerce sites not only use word-of-mouth effect, but also use the original six-degree division theory of social network to help enterprises find customers. Thus, for ecommerce enterprises, the use of social network has two major advantages: first, the use of word of mouth to facilitate transactions; second, they use relationships to help members in e-commerce companies expand their markets.

The Alibaba e-commerce ecosystem can be the best users of social networks, but its aim is to form an e-commerce ecology, attempted to seize the commanding heights of competition, practitioners have to alert. In the Alibaba B2B social network, it has introduced "connections," to establish the relationship between $\mathrm{B}$ and $\mathrm{B}$, help potential customer relationship from mining business connections to aid in classifying customers to manage them more effectively.

In the social networking aspects of $\mathrm{C} 2 \mathrm{C}$, Taobao launched "tao river's lake," can launch "ask," to ask or check your friends on the value of a product or service through "pick me to ask friends to help you choose goods or you choose to help a friend goods, published by "rink hijinks" yourself for the product evaluation, and so on. These initiatives further cement the importance of word of mouth and how social networks play a crucial role.

In word-of-mouth, he provides users with ali "relationship" service, you can create your-self for a life of the dealer evaluation or view the evaluation of a friend, to help others is a better decision. Alibaba's three e-commerce social networking services have taken form. Once Alibaba integrates three social networks into one large social network, Alibaba's e-commerce ecosystem will become more "systematic" and likely to dominate the competition.

Google is all about advertising, all of its free services such as Google Analytics, Ad Planner, Ad Builder as well as the acquisition of Double Click and YouTube, etc., are a part of its advertising business ecosystem. Alibaba similarly has sought to go beyond electronic commerce, trying to build an ecosystem, and its social networking initiatives have made it clear what its future direction is.

\subsubsection{From a Technological Perspective}

The improvement of online payment methods will further promote the development of e-commerce. Online payment information search, ordering, payment and logistics delivery are three links of ecommerce transactions, among which payment is an important link, which affects other links of e- 
commerce. Online payment has unparalleled advantages over traditional payments. As laws and regulations are made to secure payment protocols, internet payment will become the preferred method of payment in electronic commerce and pay for the rapid development of internet will promote the development of electronic commerce.

\subsubsection{B2B B2C C2C Convergence will Become the Trend}

Many professional merchants appear on eBay as individual sellers, and business-to-business transactions that should have been $\mathrm{B} 2 \mathrm{C}$ are now $\mathrm{C} 2 \mathrm{C}$. This convergence is fundamental in internet transactions, in which both parties value convenience and security of the transaction platform more than the identity of the other party, whether it is a per-son or a business.

In this situation, more $\mathrm{B} 2 \mathrm{C}$ e-commerce sites are providing platforms for $\mathrm{C} 2 \mathrm{C}$ transactions. At the same time, an increasing amount of $\mathrm{B} 2 \mathrm{C}$ transactions with payment tool $\mathrm{P} 2 \mathrm{P}$, from the third-party payment tool providers, break down the barriers between $\mathrm{B} 2 \mathrm{~B} \mathrm{~B} 2 \mathrm{C} \mathrm{C} 2 \mathrm{C}$ pay, which is an important factor in their appeal. China's B2C website Dangdang plans to enter the $\mathrm{C} 2 \mathrm{C}$ space, a trend that will intensify in the future. Along with the integration of payments, the continuous development of thirdparty payment platform and the intensification of mutual competition.

China now has the most third-party payment platforms in the world, in China alone has nearly 50 institutions that have launched their own internet payment tool, paid by different shopping websites using different tools to provide more convenience for users. There-fore, it is inevitable for payment platforms to integrate several payment tools through competition and survival of the fittest. From the point of competition, with its own auction site payment will establish an advantage in the competition, and further expand their market share (such as Paypal and Alipay), while pure third-party platform will be at a disadvantage in terms of costs and fees.

\subsubsection{Advanced Technology Will Innovate Payments}

In the field of security certification, single mode authentication was replaced by two-factor authentication. Modern technologies such as fingerprint recognition, voice recognition, iris recognition and other biological technologies will be more widely used in the financial services industry. Ucb adopted Digital Persona's $U$ are $U$ online fingerprint identification solution, which eliminates the need for a password to log onto a Web page. Comdot is rolling out a voice-activated credit card called Beepcard, which must be authenticated by voice input. With the development of more advanced technology internet payments will be more secure and used among online consumers worldwide.

The continuous improvement of laws and regulations will promote the development of the online payments sector.

China and the United States have created legislature through implementing electronic signatures, determine the legitimacy of electronic signature, improve the legal environment of online payment, and promote the development of online payments. The electronic commerce network involves the transfer of funds, payment to financial regulators to third-party payment platform, operation specification high attention, and further perfecting the system to access, to maintain the stability of the market, promote legal compliance management. China's internet payment infrastructure will play an increasingly important role in the international payment network.

\subsubsection{From Globalization View}

The broad market prospect of e-commerce in China has attracted many foreign e-commerce websites to enter the market. Amazon acquired joyo, China's largest B2C website, and Yahoo bought a 35\% stake in Alibaba, the country's largest business-to-business website.

The development of e-commerce will certainly affect the development of China's online payment market. China's internet payment methods are playing an increasingly important role in the international payment network. In order to solve the problems of the electronic commerce security trading, China Unionpay CUPSecure launched an e-commerce security certification system, to the Chinese e-commerce transactions and a safe protection lock. This has contributed to the end of the long-term use of financial institutions abroad VISA, MC of 3 - D which was once standard. 


\section{Discussion and Conclusion}

From the analysis and comparison above, it is clear that China's e-commerce development has room for improvement, while e-commerce in the US has reached a relatively mature and developed stage. China is a representative of Asian developing countries, and the U.S has the greatest power of affecting the global market. We also found that, China has to solve problems such as security in electronic trading platforms, immature and stagnant credit systems, and insufficient logistics distribution systems. However, be-cause of the high population growth rate, increasing access to the internet, technological and legal support, China has the potential to catch up and close the gap.

\subsection{China}

China is in the midst of a consumer revolution, with foreign products taking advantage of heavily investing in marketing, advertising and research to create more effective marketing strategies. Brand awareness is important and sophisticated advertising plays a key role in attracting Chinese consumers. Producers of luxury goods and providers of services have seen large growth in China as a result.

Chinese society is often perceived as a "collectivist" society, where the group is more important than the individual. As a result, standards, preferences and standards of the group to which the individual belongs have a tremendous effect on purchasing habits.

The golf craze - with over a million taking up the sport in recent years - is an example of the desire to belong to a group (the affluent) and subsequent conformity to the preferences of this group. As a result, advertising is frequently directed at groups, rather than individuals.

Chinese consumers tend to be brand-sensitive. They believe price is an indicator of the quality of a product, though both price and sales are important selection criteria. Aspects such as warranty and possibility of product refund are less important. Generally, Chinese shoppers attach greater importance in researching a product before purchasing it. A majority of the source of their information is word of mouth.

\subsection{US}

$29 \%$ of US consumers (aged 16-21) browse online stores, even when they do not have a product in mind. For adult shoppers ages $22-65$, the number is $18 \%$. In addition, US consumers are open to buying foreign products. US consumers are becoming more aware of environmental issues and over consumption. They pay more attention to the quality of a product, its origin, how it is composed and the price. The most important characteristic in shopping is finding a "good deal." This creates a euphoric experience for a potential customer that could lead to a sale.

\section{References}

[1] China B2C E-Commerce Market 2015. 2016

[2] Global Cross-Border B2C E-Commerce 2015: Global Cross-Border B2C E-Commerce Growing at Double-Digit Rates. 2015

[3] Jing Zhao, Shan Wang, Wilfred V. Huang. A study of B2B e-market in China: E-commerce process perspective. Information \& Management. 2008

[4] Jen-Her Wu, Qi Li \& Kwok Kee Wei. Alibaba's IT platform and electronic commerce synergy in driving "Singles' Day". Journal of Organizational Computing and Electronic Commerce. 2016

[5] Maria Giuffrida, Riccardo Mangiaracina, Alessandro Perego and Angela Tumino. Cross-border B2C e-commerce to Greater China and the role of logistics: a literature review. International Journal of Physical Distribution \& Logistics Management. 2017

[6] Nitish Singh, Vikas Kumar, Daniel Baack. Adaptation of cultural content: evidence from B2C ecommerce firms. European Journal of Marketing. 2004 
[7] Qiu Bin;Chen, Shu-Jen;Shao Qin Sun. Cultural differences in e-commerce: A comparison between the U.S. and China. Cultural Differences in E-Commerce: A Comparison Between the U.S. and China. 2003

[8] Zhao Li, Shujian Wang. The Foundation of E-commerce: Social Reputation System - A Comparison between American and China. 2015

[9] Zhao Jingqiao. Study on China's E-Commerce Service Industry: Current Situation, Problems and Prospects. The Chinese Economy. 2017 